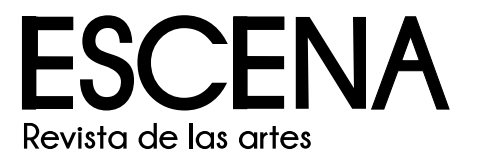
Publicación semestral. ISSN 2215-4906
Volumen 80 - Número 2
Enero - Junio 2021

\title{
¿ARTE CONTEMPORÁNEO LATINOAMERICANO? PRESENTACIÓN AL DOSSIER
}

\author{
Sergio Villena Fiengo
}

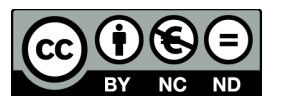

Esta obra está bajo una licencia Creative Commons

Reconocimiento-No comercial-Sin Obra Derivada 
Editorial

\section{¿ARTE CONTEMPORÁNEO LATINOAMERICANO? PRESENTACIÓN AL DOSSIER}

\section{Sergio Villena Fiengo ${ }^{1}$}

"Arte contemporáneo Latinoamericano". Pero: ¿qué es el arte? ¿Qué es lo contemporáneo? ¿Cómo definir lo latinoamericano? En fin, ¿qué es el arte contemporáneo en/desde/para América Latina? Este dossier ofrece un conjunto de aproximaciones al universo cultural que se configura cuando los tres términos incluidos en el sintagma arte latinoamericano contemporáneo se anudan o entreveran dialécticamente unos con otros, estableciendo tensiones creativas que iluminan fugazmente nuestro presente incierto.

La contemporaneidad. El filósofo Gorgio Agamben se pregunta, desde un transfondo que pone en relación las reflexiones de Nietzsche con las de Walter Benjamin: "¿de quién y de qué somos contemporáneos? Y, ante todo, ¿qué significa ser contemporáneos?". La contemporaneidad, responde, "es esa relación singular con el propio tiempo, que se adhiere a él pero, a la vez, toma distancia de éste; más específicamente, es esa relación con el tiempo que se adhiere a él a través de un desfase y un anacronismo". Ser contemporáneo, diría Walter Benjamin, es recorrer el presente a contrapelo.

La contemporaneidad del arte no es, entonces, una mera cuestión cronológica. Por tanto, no puede resolverse con la frase "contemporáneo es el arte que se está haciendo ahora" o "contemporáneo es el arte que están creando los y las artistas que están vivos(as)". El adjetivo "contemporáneo" aplicado al arte posee profundas implicaciones filosóficas y políticas que se pueden esbozar, con fines heurísticos y de manera preliminar, en los siguientes términos: contemporáneo es el arte -entendido como un conjunto de prácticas sociales que trabajan en torno a la articulación dialéctica entre conceptos, emociones y formas sensibles- que se está haciendo ahora y responde críticamente a los desafíos del presente, que establece una relación políticamente productiva respecto al mismo.

¿Arte contemporáneo latinoamericano? Esa doble adjetivación plantea la cuestión de definir la relación del arte con su propio tiempo (contemporáneo), sino también con su referente geográfico (latinoamericano). En el marco de la brevedad que impone una presentación, puede parecer desmesurado -aunque sin duda inevitable- formular la pregunta de qué es el arte latinoamericano, es decir, interrogarnos sobre cuáles son las maneras en

1 Profesor catedrático de la Escuela de Sociología y Director del Instituto de Investigaciones Sociales de la Universidad de Costa Rica (UCR). Doctor en Estudios de la Sociedad y la Cultura por la UCR. ORCID: 0000-0002-2864-8816. Correo electrónico: sergio.villena@ucr.ac.cr 
que el arte que se hace hoy en nuestra región imagina e interviene sobre nuestro presente latinoamericano.

Entonces ¿qué es el arte latinoamericano? ¿Es el arte que se hace en América Latina? ¿La práctica social que utiliza cierto tipo de lenguajes artísticos para explorar la realidad latinoamericana? ¿La práctica artística de quienes viven y trabajan aquí o, al menos, se consideran a sí mismos latinoamericanos? Para comenzar desde el principio: ¿qué es Latinoamérica? ¿Una geografía, una cultura, una historia? ¿Una particular (y quizá imposible) forma de articulación -heterotópica y heterocrónica- entre geografías, culturas, historias? ¿Es una comunidad imaginada, una aspiración, una construcción o una frustración? ¿Por qué latino y no ibero, hispano, indo, indo-afro-ibero o simplemente Abya Yala?

Para complejizar aún más este ejercicio: ¿cómo se define lo contemporáneo cuando se habla del arte latinoamericano? ¿Cuál es el lugar de América Latina en la contemporaneidad? Más aún ¿Es posible ser latinoamericano y contemporáneo? O, como se ha pensado desde algunas perspectivas que ahora se tienden a denominar coloniales, ¿lo latinoamericano se define más bien por la imposibilidad de ser contemporáneo, por un insalvable anacronismo o, quizá, por la sobreposición dislocada de tiempos? ¿Para ser contemporáneo en América latina es necesario -como sugiere Gerardo Mosquera- superar la "neurosis por la identidad" que ha caracterizado a lo que históricamente conocemos como arte latinoamericano? ¿Puede América Latina -o la búsqueda de una identidad latinoamericana- ser un anacronismo productivo? ¿Cómo contribuye el arte contemporáneo -como señala García Canclini- en la búsqueda de un lugar propio para Latinoamérica en este siglo?

En fin: ¿cuál es el potencial crítico del arte latinoamericano como anacronismo de lo contemporáneo? ¿Cómo el arte producido en/desde/ para esta geografía y tiempo latinoamericano puede dislocar el mapamundi y el reloj universal? Parafraseando a Borges, se podría decir: "ignoramos si el arte latinoamericano contemporáneo es posible, ignoramos si el arte latinoamericano es posible, ignoramos si el arte mismo -reiteradamente declarado 'muerto'- es todavía posible”. Precisamente, nuestro punto de partida en esta búsqueda es esa ignorancia inquieta que se vuelca en tres interrogantes y sus entrelazamientos problemáticos, los cuales sirven como acicates para la exploración de ese oscuro objeto de estudio que es el arte contemporáneo latinoamericano o el arte latinoamericano contemporáneo: ¿qué es el arte? ¿Qué es lo contemporáneo? ¿Qué es lo latinoamericano?

El dossier que presentamos tiene como pretención aportar a la reflexión colectiva e informada sobre esa compleja problemática, propósito con el cual reune un conjunto de valiosas contribuciones que, desde perspectivas y lugares diversos, abordan la producción de un conjunto de artistas latinoamericanes que, siguiendo las reflexiones previas, pueden ser calificados como contemporáneos. 
El primer artículo, escrito por Jorge Marchena, realiza una aproximación a uno de los colectivos pioneros del arte contemporáneo latinoamericano, el Grupo CADA, destacado por su labor de crítica a la dictadura de Pinochet. Los tres artículos siguientes posan su mirada analítica sobre la obra de mujeres artistas latinoamericanas y dan relevancia el protagonismo femenino y feminista en el arte contemporáneo de la región: Guiselle Hidalgo y Dorde Cuvardic estudian la obra de Adriana Bustos (Argentina), Marcela Otárola reflexiona sobre el trabajo de Regina Galindo (Guatemala) y Sindy Mora enfoca su mirada crítica sobre la inserción de Teresa Margolles (México) en los circuitos comerciales del arte global. Estos cuatro artículos se gestaron durante las conversaciones que compartimos en el curso "Arte y sociedad en América Latina: Una aproximación desde lo contemporáneo", impartido el Doctorado en Estudios de la Sociedad y la Cultura (Universidad de Costa Rica), durante el segundo semestres del año 2018.

La siguiente contribución es de mi autoría; en esta reflexiono sobre la obra del artista costarricense Oscar Figueroa. La obra de este artista aborda un conjunto de problemáticas que guardan relación con las cuestiones contemporáneas que articulan la violencia de la globalización neoliberal con las herencias coloniales y republicanas. Cierran este dossier dos artículos aportados desde América del Sur. En el primero, Raiza Ribero Calvacanti y María Teresa Barboza de Oliveira, estudian el Museo de la Dignidad y los desafíos que plantea el estallido político-expresivo acontecido en Chile hacia fines de 2019 a la reflexión sobre la contemporaneidad artística y su patrimonialización cuando la práctica artística desborda los espacios institucionalizados, toma la calle y deviene herramienta de los movimientos sociales y la ciudadanía movilizada. El dossier cierra con un texto enviado desde Uruguay por Federico Sequeira, en el cual analiza la relación entre arte contemporáneo y movimientos sociales, prestando especial atención también a los primeros efectos de la pandemia sobre el arte contemporáneo de la región.

Precisamente, cuando el dossier que hoy ESCENA. Revista de las artes pone a disposición del público estaba ya en periodo de cierre, irrumpió la pandemia y las medidas implementadas para atenuar sus efectos y, no menos importante, capitalizar políticamente esa inesperada circunstancia. Como han hecho evidente una serie de foros virtuales y publicaciones realizadas en estos meses, en toda la región latinoamericana -y en general en el ámbito global- el sector cultura fue uno de los más inmediata, profunda y duraderamente afectados por las medidas de restricción del movimiento, distanciamiento social y ajustes presupuestarios implementados por los gobiernos. Por contraparte, el sector cultura fue uno de los primeros en responder solidariamente a la situación de cuarentena, poniendo en circulación diversidad de contenidos, en general de manera gratuita. 
Los gobiernos, por su parte, en el mejor de los casos crearon algunos fondos o ayudas para atender la situación crítica en que se vieron repentinamente las y los creadores y las instituciones de la cultura. Sin embargo, esas medidas fueron en la generalidad insuficientes y pronto dieron lugar a recortes presupuestarios y puesta en cuestión de la obligación del Estado para garantizar el derecho a la cultura. Todo eso ha afectado las condiciones institucionales, materiales y subjetivas para la creación y la circulación de arte contemporáneo, esa parte crítica de la cultura, que aspira a iluminar el lado oscuro que se oculta detrás del aura de la tradición y de lo consagrado. No obstante, a la vez, la complejidad y gravedad de esta crisis múltiple (sanitaria, social, económica y cultural) ha dado lugar a una perplejidad que demanda, hoy más que nunca, respuestas desde el arte contemporáneo.

¿Cuáles son los retos que nos plantea nuestro presente? ¿Cómo puede el arte contemporáneo contribuir a plantar cara a esos retos? Nuestra contemporaneidad pandémica plantea una serie de grandes desafíos sociales, que exigen búsquedas formales y exploraciones conceptuales que convocan al arte: la defensa de la vida digna, la protección de lo común, la inclusión democrática, el combate a la desigualdad social y la defensa de los derechos humanos, incluido el derecho a la cultura, entre otros. Esperamos que los artículos incluidos en este dossier, más allá de su evidente aporte al análisis e interpretación de producciones artísticas específicas, constituyan también una invitación a comprender y promover la relevancia social y política del arte contemporáneo como herramienta para pensar e imaginar creativa y críticamente la compleja e incierta contemporaneidad latinoamericana. 